\title{
Kardiyak Yaralanmalar
}

\author{
Cardiac Trauma
}

\author{
Berk Özkaynak1, Funda Gümüş², Adil Polat' ${ }^{1}$ Nihan Kayalar1', Vedat Erentuğ ${ }^{3}$ \\ 'Bağcılar Eğitim ve Araştırma Hastanesi, Kalp ve Damar Cerrahisi Kliniği, İstanbul, Türkiye \\ ${ }^{2}$ Bağcılar Eğitim ve Araştırma Hastanesi, Anestezi ve Reanimasyon Kliniği, İstanbul, Türkiye \\ ${ }^{3}$ Erzincan Üniversitesi Tıp Fakültesi, Kalp ve Damar Cerrahisi Anabilim Dalı, Erzincan, Türkiye
}

\section{ÖZET}

Kalp ve büyük damar yaralanmaları künt, penetran veya iatrojenik nedenlere bağlı olabilir. Travmaya bağlı ölümlerin yaklaşık \% 25 'i toraks yaralanmalarına bağlıdır. Künt yaralanmaların en sık nedeni yüksek enerjili trafik kazalarıdır. Bu hastaların \%5'i müdahale şansı bulabilmektedir. Künt travma hikayesi olan hastalar, semptomatik olsun veya olmasın, miyokard enfarktüsü geçirmiş veya geçirmekteymiş gibi çok yakından takip edilmelidir. Künt travmaya bağı perikardiyal ve epikardiyal kanama, miyokard kontuzyonu ve nihayetinde miyokardda laserasyon oluşur. Ventrikül ve atrial rüptür, atriyoventriküler septumda, ventriküler septumda rüptür, papiller adalelerde rüptüre bağlı mitral veya triküspid kapaklarda akut yetmezlik, koroner arterlerde fistülizasyon, laserasyon ve/veya tromboz, pulmoner venlerde rüptür gözlenebilir. Penetran yaralanmalar kesici delici alet ve ateşli silah ile yaralanmalara, iatrojenik, tanısal veya tedavi amaçlı girişimlere bağlı, oluşabilir. Kalp yaralanmalarında, hastanın travma bölgesinden müdahale edileceği merkeze en hızlı şekilde sevk edilmesi bu hastalar için hayatta kalımı etkileyen en önemli faktördür. Belirgin şok ve/veya tamponad bulgusu olan hastalarda ileri tetkik beklenmeden, ameliyathaneye alınarak müdahaleye başlanmalı, gerekirse sıvı yollarının yerleştirilmesi beklenmeden cerrahi girişime başlanmalıdır. Basit yaralanmalar, primer olarak onarılabilirse de çok büyük miyokard hasarlanmasında veya intrakardiyak yaralanmalarda (valvül hasarı, septal defekt oluşumu, eşlik eden ve koroner arter bypass gerektiren durumlar, vb.) kardiyopulmoner bypass altında onarım gerekebilir. Hemodinamisi stabil olan hastalarda ise ilk 48 ile 72 saat çok yakın takip şarttır. (JAREM 2014; 2: 45-8)

Anahtar Sözcükler: Kardiyak travma, kardiyak yaralanma, künt travma, penetran yaralanma

\begin{abstract}
Advances in cardiac surgery over the past decades have enabled more efficient, complex and successful repairs of cardiac injuries. Cardiac injuries may be caused by blunt, penetrating or iatrogenic trauma. $25 \%$ of the trauma related deaths are caused by chest trauma. The lethal nature of this injury is due to the high concentration of major vascular and visceral structures within the mediastinum. The most common cause of blunt cardiac injury is high impact motor vehicle accidents. Other sources of blunt cardiac trauma are falls from heights, crush injuries and athletic injuries. Only $5 \%$ of these patients would receive medical intervention. Blunt trauma causes pericardial and epicardial hemorrhage and myocardial contusion. Myocardial contusion may range in severity from minor subepicardial hematoma to larger extravasations including the full thickness of the myocardium. Larger contusions lead to necrosis which may heal by scarring or may lead to lethal rupture of the myocardium. Rupture in the ventricles, atria, atrioventricular septum and pulmonary veins can be seen. Rupture in papillary muscles may lead to acute mitral or tricuspid failure. Fistulization, laceration and thrombosis in the coronary arteries may lead to further myocardial injury necessitating coronary artery bypass surgery. Patients with blunt cardiac trauma, either symptomatic or asymptomatic, should be monitored closely for possible complications of myocardial contusion. Penetrating cardiac injuries may be caused by gunshot wounds or stab wounds. latrogenic injuries may be encountered most commonly during catheterisation procedures and reoperations due to excessive adhesions caused by previous operations. Major factor affecting survival of these patients is the duration of transport from the scene of trauma to the medical center for interventions. Patients with prominent signs of cardiac tamponade should be taken into the operating room promptly and treated without necessitating further diagnostic tools. Emergency thoracotomy or sternotomy may be instituted to decompress the heart and control possible hemorrhage. In severe hypovolemic shock, emergency sternotomy may be performed before placement of intravenous lines and volume replacement with crystalloids, colloids and blood can be administered directly into the right atrium through large bore needles. Simple injuries may be repaired primarily with careful monitoring and stabilization of hemodynamics. In cases of larger defects or complex injuries such as valvular disruption and acute failure, injury of coronary arteries necessitating coronary artery bypass surgery and atrioventricular septal defects, cardiopulmonary bypass may be used to avoid further myocardial injuries. Close monitoring of asymptomatic cardiac trauma patients for at least 48 to 72 hours after admission for possible complications and aggressive and rapid intervention in patients with manifest symptoms are vital for survival and effective treatment of cardiac injuries. (JAREM 2014; 2: 45-8)
\end{abstract}

Key Words: Cardiac trauma, blunt trauma, penetrating trauma, cardiac injury

Aristotales "tüm organlar içinde, kalbin, ciddi bir yaralanmaya dayanamayacağını" yazmış ve 1800'lü yılların sonlarına dek kardiyak yaralanmalara müdahale şansı olmadığı düşünülmüştür (1). Bu dönemde yapılan hayvan çalışmalarının ve gözlemlerin ardından 1896'da Rehn, insanda ilk başarılı kardiyak onarımı gerçekleştirmiştir (2). Takip eden yıllarda, savaşlarda kazanılan deneyimler ve kalp cerrahisindeki gelişmeler ile bu yaralanmalara müdahale şansı ve başarı gittikçe artmıştır.
Kalp ve büyük damar yaralanmaları künt, penetran veya iatrojenik nedenlere bağlı olabilir. Travmaya bağı ölümlerin yaklaşık \%25'i toraks yaralanmalarına bağlıdır (3). Çok merkezli bir çalışmada, toraks yaralanmalarında acil cerrahi müdahale ihtiyacının, künt travmalarda \%0,5, penetran yaralanmalarda \%2,8 olduğu bildirilmiştir (4). Silahlı yaralanmalarda, hastaların \%50'sinde müdahale gerektiren kardiyak ve damar yaralanması saptanırken, bunlarda mortalite oranları \% 40 'lara ulaşmaktadır (5). 


\section{Künt Kalp Yaralanmaları}

Künt yaralanmaların en sık nedeni yüksek enerjili trafik kazalarıdır. $\mathrm{Bu}$ hastaların çoğunluğu travma esnasında veya hastaneye nakil edilene kadar hayatını kaybetmekte ancak \%5'i müdahale şansı bulabilmektedir (6). Hayatta kalanlarda, sırasıyla en sık sağ atrium, sağ ventrikül, sol atrium ve sol ventrikülde hasarlanma tesbit edilmiştir (7). Postmortem incelemelerde ise her dört boşluğun da eşit oranda etkilendiği bildirilmiştir $(8,9)$. Torasik aort yaralanması olan hastalarda künt kalp yaralanması insidansı \%3.6 ile \%63 arasındadır $(10,11)$. Torasik aort yaralanması olan hastalarda künt kalp yaralanması sıklığı, torasik aort yaralanması olmayan travmalı hastalara göre daha yüksektir (12).

Yapılan çalışmalarda kalbin künt travmaları çok iyi tolere ettiği, ancak aktarılan enerji arttıkça erken dönemde perikardiyal ve epikardiyal kanama, miyokard kontuzyonu ve nihayetinde miyokardda laserasyon oluştuğu bildirilmiştir (8). Geç dönemde hasarlı miyokardda kısmi veya tam kat enfarkt oluşumu saptanmış, enfarkt sahasının endokard yüzünde mural trombus varlığı gösterilmiştir $(8,9)$.

Künt travma ile oluşan yaralanmalarda mekanizmalar, kalbin sternum ve omurga arasında sıkışması, ivmelenme kaynaklı ters kuvvetler, kırılan kemiklerin direkt hasarı, hidrolik çarpma etkisidir (çarpma sonucu kalp boşluklarında basıncın çok hızlı ve yüksek değerlere ulaşması) (7).

Künt travma hikayesi olan hastalar, semptomatik olsun veya olmasın, miyokard enfarktüsü geçirmiş veya geçirmekteymiş gibi çok yakından takip edilmeli (8), miyokard kontuzyonuna bağlı oluşabilecek supraventriküler, ventriküler aritmilere karşı hazırlıklı olunmalıdır. Akut komplikasyonlar künt travmalı hastaların \%15 ile 68'inde oluşmakta, bunların da yarısında tedavi ihtiyacı oluşmaktadır. Diğer tüm komplikasyonlar da yaralanma sonrası ilk 24 ile 72 saatte ortaya çıkmaktadır (13). Çalışmalarda bu hastaların ayrımı ve takibi ile ilgili standart bir yaklaşım sunulamasa da, yaralanma sonrası ilk 48 ile 72 saatlik dönemdeki yakın izlem çok önemlidir (14-16). Bu hastalarda temel olarak fizik muayene, elektrokardiyografi (EKG), ekokardiyografik değerlendirmeler ve takipler hızlı tanı konulmasında yardımcıdır. Kardiyak tamponad bulguları saptanan hastalarda acil perikardiyosentez uygulanmalıdır. Akut kardiyak tamponadda, röntgen filmlerinde kalp silüetinde genişleme gözlemlenmeyebilir. Hemotoraks ve hipovolemik şok tablosunda mutlaka büyük sıvı yolları yerleştirilerek kolloidler ve kan transfüzyonları ile kan kaybı karşılanmalıdır. Çok akut gelişen tamponadlarda, sıvı yolu yerleştirilecek zaman olmayabilir. Bu durumlarda, hızlı sternotomi veya torakotomi sonrası perikard açılıp, sağ atriumdan direkt olarak büyük boy bir iğne ile hızlı replasman sağlamak mümkündür.

Ventrikül ve atrial rüptürlerde direkt onarım mümkündür. Perikardiyal rüptür diyafragmatik ve plevral bileşkelerde oluşabilir. Diyafragmatik perikardiyal rüptür, batın içeriğinin fıtıklaşmasına ve basıya bağlı kardiyojenik şoka neden olabilir. Plevral perikardiyal rüptürde ise kalp plevral boşluklara doğru fıtıklaşarak konstriksiyona, strangulasyona veya torsiyona uğrayabilir (17). Atriyoventriküler septumda, ventriküler septumda rüptür, papiller adalelerde rüptüre bağlı mitral, triküspid kapaklarda akut yetmezlik oluşabilir $(18,19)$. Koroner arterlerde fistülizasyon, laserasyon ve/veya tromboz oluşabilir (20). Pulmoner venlerde de rüptür gözlenebilir (21). Künt travmaya bağlı en sık etkilenen kapak yapıları sırası ile aort kapak, mitral kapak ve triküspid kapaktır (22).
Künt kardiyak travmanın uzun dönem etkilerine ilişkin yayınlarda, künt travma sonrası akut komplikasyon gelişmemiş ancak ventrikül fonksiyonlarında bozulma (miyokard kontüzyon) saptanmış hastaların büyük çoğunluğunda bir yıl içinde kardiyak fonksiyonlarda kabul edilebilir iyileşme olduğu saptanmıştır $(23,24)$.

\section{Penetran Kalp Yaralanmaları}

Penetran toraks yaralanmalarının \%6'sı kalp yaralanmalarına neden olmakla birlikte, penetran toraks yaralanmalarının \%50'si kalp yaralanmalarına bağlı ölümle sonuçlanmaktadır (20). Kesici delici alet ve ateşli silah ile yaralanmalara bağlı olabilir. Gelişmiş ülkelerde çoğunlukla ateşli silah yaralanmalarına bağlı görülse de gelişmekte olan ülkelerde ve ülkemizde daha çok kesici delici alet yaralanmasına bağlıdır (16, 20, 25). Bu farklılık gelişmiş ülkelerde ateşli silahlara erişimin daha kolay olması kadar gelişmekte olan ülkelerde ateşli silah ile yaralananların zamanında müdahale şansı bulamamalarına da bağlı olabilir. Penetran kalp yaralanmaları iatrojenik, tanısal veya tedavi amaçlı girişimlere bağlı da oluşabilir. Kalp kateterizasyonu esnasında, koroner anjioplasti, stent uygulamaları, pace-maker lead implantasyonu, balon valvuloplasti gibi invaziv girişimler sırasında travma oluşabilmektedir. Kardiyopulmoner resüsitasyonda sternum ve kot kırıklarına ve kardiyak masaja bağlı yaralanmalar oluşabilir. Perikardın kalbe yapışık olduğu (geçirilmiş operasyon, enfeksiyon, radyoterapi veya geçirilmiş travma vb.) durumlarda, cerrahi işlem esnasında kardiyak yaralanma meydana gelebilmektedir.

Penetran yaralanmalarda sırası ile en sık sağ ventrikül, sol ventrikül, sağ atrium ve sol atrium etkilenir (16, 26-28). Kalbin serbest duvarları en çok etkilense de kapak yapılarında, papiller kaslarda, korda tendinealarda, ventriküler veya atriyal septumda ve koroner arterlerde de hasar oluşabilir (16).

Penetran kalp yaralanmalarında hızlı tanı ve tedavi hayat kurtarıcıdır. Bu yaralanmaya bağlı ölümlerin büyük çoğunluğu, hastanın olay yerinden hastaneye ulaştırılmasına kadar geçen sürede gerçekleşmektedir. Hastaların klinik durumu yaralanmanın şekline, hastaneye ulaşılana kadar geçen süre, hastaneye ulaşmasından ameliyathaneye alınana kadar geçen süre, kardiyak tamponad varlığı ve eşlik eden yaralanmaların sayısına göre değişkenlik gösterebilir (29). Hastaneye ulaştırılan ve acil ameliyata alınabilen hastaların \%74'ünün hayatta kalabildiği bildirilmiştir (30). Ciddi şok veya belirgin kardiyak tamponad bulguları olan hastalar ek tanısal işlemler uygulanmadan acil operasyona alınmalıdır. Belirgin klinik bulgusu olmayan hastaların tanısı oldukça zordur. Travma durumlarında, ani gelişmiş tamponadda Beck üçlemesi değerlendirmede güvenilir değildir. Ayrıca bu hastalarda EKG ve röntgen bulguları tanıda yardımcı olmayabilir. Santral venöz basınç ölçümlerinde de yanılma payı, bu tip acil hastalarda yüksek bulunmuştur. Transtorasik ekokardiyografi, subxiphoid perikardiyal pencere açılması tanıda oldukça yardımcı bulunmuştur (31).

Hemoperikardiumu olan ancak hemodinamisi stabil izlenen, tamponad bulgusu olmayan hastalar operasyona alınmadan izlenebilir. Bu hastaların yakın kan basıncı, idrar çıkışı, santral venöz basınç, EKG ve hemoglobin düzeyi takibi şarttır.

Hemodinamisi stabil izlenmeyen, tamponad bulguları veya şüphesi olan hastalar acil operasyona alınarak median sternotomi veya torakotomi ile dekompresyon sağlanmalıdır. Kalp ve mediastenin 
eksplorasyonu için çeşitli yaklaşımlar sunulsa da, hangisinin uygulanacağı genelde cerrahın deneyimine ve her bir tekniğin sunduğu avantaja göre belirlenir. Posterolateral torakotomi plevral boşluğu çok iyi ortaya koyarken, kalbe ulaşmayı zorlaştırabilir. Anterolateral torakotomi ile kalbe ve plevraya iyi bir yaklaşım mümkündür. Gerektiğinde insizyon karşı tarafa doğru genişletilebilir (clam-shell insizyonu) veya parsiyel sternotomi eklenerek yaralı bölgelere kolayca ulaşılabilir. Ancak sternum ve toraksın kapatılması problemli olabilir. Median sternotomi optimal kardiyak ve plevral yaklaşım sunar ancak her merkezde uygulanamayabilir, kalp cerrahisi merkezlerinde genelde tercih edilen bir yaklaşımdır. Ne şekilde olursa olsun perikarda ulaşılır ulaşılmaz dekompresyon yapılmalı, perikard boşluğu açılarak kalp rahatlatılmalı eş zamanlı kanama kontrolü yapılmalıdır. Kanamayı geçici olarak durdurmak için foley sonda kullanımı, cilt stapleri uygulaması gibi yöntemler önerilmiştir (32-34). Ancak bunlar miyokardda daha çok hasara neden olabilir. Basit dijital kompresyon ile geçici olarak kanama durdurmak basit ve etkili bir yöntemdir (35). Atriyum yaralanmalarında vasküler klamp uygulanarak, 3/0 ya da 4/0 polipropilen sütürlerle onarım yapılabilir. Basit miyokard laserasyonları 2/0 veya 3/0 tek tek dikişler ile miyokarddan tam kat geçilerek onarılabilir. Koroner damarlara yakın bölgedeki laserasyonlarda, matris sütürler damarın altındaki miyokard dokusundan, kan akımını engellemeyecek şekilde geçilmelidir. Koroner arterlerde yaralanma varsa koroner bypass uygulanması gerekebilir. Çok büyük miyokard hasarlanmasında veya intrakardiyak yaralanmalarda (valvül hasarı, septal defekt oluşumu, vb.) kardiyopulmoner bypass altında onarım gerekebilir. Kalbin arka yüzündeki yaralanmaların onarımı güç olabilir. Kalp kaldııldığında hipotansiyon, bradikardi ve arrest ortaya çıkabilir. Bu tür onarımlarda, kalbin tolere ettiği ölçüde kısa aralıklarla kalp kaldırılıp tekrar hemodinami toparlayana dek bekleyerek, her seferinde hasarın yerinin tesbiti, sütürlerin geçilmesi ve bağlanması yavaş yavaş yapılarak onarım gerçekleştirilebilir (35). Bu durumlarda, kalp hızını yavaşlatıp kısa süreli asistoli sağlaması için adenosine infüzyonu uygulanabilmektedir (36).

\section{SONUÇ}

Ne tür travma olursa olsun, kardiyak yaralanma şüphesi olan hastalar en kısa sürede müdahale şansı olan bir merkeze sevk edilmeli, bu süre içinde de gerekli yardımcı tedaviler uygulanmalıdır. Belirgin şok ve/veya tamponad bulgusu olan hastalarda ileri tetkik beklenmeden, ameliyathaneye alınarak müdahaleye başlanmalı, gerekirse sıvı yollarının yerleştirilmesi beklenmeden sternotomi yapılmalı ve açık şekilde sıvı resussitasyonuna başlanmalıdır. Basit yaralanmalar, primer olarak onarılabilirse de gerektiğinde kardiyopulmoner bypass altında müdahale de yapılabilir.

Hemodinamisi stabil olan hastalarda ise ilk 48 ile 72 saat çok yakın takip şarttır. Perikard boşluğu, ani olarak 80 ile 100 ml'ye kadar bir hacim birikimini, fizyolojik olarak negatif olan, intraperikardiyal basıncı (IPB) etkilemeden tolere edebilir. Bu hacmin üzerindeki her küçük artış, IPB'ı çok yüksek değerlere çıkarır. Yeterli kardiyak debiyi sağlayabilmek için santral venöz basınç, ventriküler dolumu engelleyen IPB'den daha yüksek olmalıdır. CVP/IPB gradiyentinin idamesi bu hastalarda önemlidir. Basınçların eşitlenmesi ve gradiyentin ortadan kalkması durumunda kardiyak tamponad ortaya çıkar. Hipovolemi, vazodilatasyon, CVP'yi düşürerek; intraperikardiyal kan birikimi ve artmış intratorasik basınç (pnömotoraks, hemotoraks) IPB'yi artırarak tamponadı artırır. Analjezikler ve kas gevşeticiler venöz tonu azaltarak, pozitif basınçlı ventilasyon da
IPB'yi artırarak CVP/IPB gradiyentini ortadan kaldırabileceğinden, müdahalelerde bu uygulamalardan kaçınmalıdır (37).

Kalp yaralanmalarında, hastanın travma bölgesinden müdahale edileceği merkeze en hızlı şekilde sevk edilmesi bu hastalar için hayatta kalımı etkileyen en önemli faktördür. Hastaneye ulaşmasından itibaren bu hastalar çok yakından izlenmeli, hemodinamik bozulma saptandığında hemen müdahale edilmelidir. Hemodinamisi stabil izlenen hastalar da en az 48 saat oluşabilecek komplikasyonlar açısından gözetim altında tutulmalıdır.

\section{Hakem Değerlendirmesi: Dış bağımsız.}

Yazar Katkıları: Fikir - B.Ö., V.E.; Tasarım - B.Ö., V.E.; Denetleme - V.E., N.K.; Kaynaklar - B.Ö., A.P.; Malzemeler - B.Ö., F.G.; Veri toplanması ve/veya işlemesi - F.G., A.P., B.Ö.; Literatür taraması - B.Ö., V.E., N.K.; Yazıyı yazan - B.Ö., A.P.; Eleştirel Inceleme - A.P., V.E.

Çıkar Çatışması: Yazarlar çıkar çatışması bildirmemişlerdir.

Finansal Destek: Yazarlar bu çalışma için finansal destek almadıklarını beyan etmişlerdir.

Peer-review: Externally peer-reviewed.

Author Contributions: Concept - B.Ö., V.E.; Design - B.Ö., V.E.; Supervision - V.E., N.K.; Funding - B.Ö., A.P.; Materials - B.Ö., F.G.; Data Collection and/or Processing - F.G., A.P., B.Ö.; Literature Review - B.Ö., V.E., N.K.; Writer - B.Ö., A.P.; Critical Review - A.P., V.E.

Financial Disclosure: The authors declared that this study has received no financial support.

Conflict of Interest: No conflict of interest was declared by the authors.

Financial Disclosure: The authors declared that this study has received no financial support.

\section{KAYNAKLAR}

1. Symbas PN, Justicz AG. Quantum leap forward in the management of cardiac trauma: The pioneering work of Dwight E. Harken. Ann Thorac Surg 1993; 55: 789-91. [CrossRef]

2. Rehn L. Ueber penetrirende Herzwunden und Herznaht. Ber Verhandl Deutsch Gesellsch Chir Leipz 1897; 26: 56-60.

3. Burack JH, Kandil E, Sawas A, O'Neill PA, Sclafani SJA, Lowery RC, et al. Triage and outcome of patients with mediastinal penetrating trauma. Ann Thorac Surg 2007; 83: 377-82. [CrossRef]

4. Karmy-Jones R, Jurkovich GJ, Nathens AB, Shatz DV, Brundage S, Wall MJ Jr, et al. Timing of urgent thoracotomy for hemorrhage after trauma. Arch Surg 2001; 136: 513-7. [CrossRef]

5. Degiannis E, Benn CA, Leandros E, Goosen J, Boffard K, Saadia R. Transmediastinal gunshot injuries. Surgery 2000; 128: 416-22. [CrossRef]

6. Fedakar R, Türkmen N, Durak D, Gündoğmuş UN. Fatal traumatic heart wounds: review of 160 autopsy cases. Isr Med Assoc J 2005; 7 : 498-501.

7. Brathwaite CE, Rodriguez A, Turney SZ, Dunham CM, Cowley R. Blunt traumatic cardiac rupture. A 5 year experience. Ann Surg 1990; 212: 701-4. [CrossRef]

8. Potter RT, Stefko PL, Bertrand CA, McNeill TM, O'Brien GF, Garret R, et al. Blunt cardiac trauma: A pathophysiological study. Ann Thorac Surg 1965; 1: 432-43. [CrossRef]

9. Bright EF, Beck CS. Nonpenetrating wounds of the heart: A clinical and experimental study. Amer Heart J 1935; 10: 293. [CrossRef]

10. Cook J, Salerno C, Krishnadasan B, Nicholls S, Meissner M, KarmyJones $R$. The effect of changing presentation andmanagement on the outcome of blunt rupture of the thoracic aorta. J Thorac Cardiovasc Surg 2006; 131: 594-600. [CrossRef] 
11. Kram HB, Appel PL, Shoemaker WC. Increased incidence of cardiac contusion in patients with traumatic thoracic aortic rupture. Ann Surg 1988; 208: 615-8. [CrossRef]

12. Kaewlai R, de Moya MA, Santos A, Asrani AV, Avery LL, Novelline RA. Blunt cardiac injury in trauma patients with thoracic aortic injury. Emerg Med Int 2011; 2011: 848013.

13. Mille FB, Shumate DR, Richardson JD. Myocardial contusion: When can the diagnosis be eliminated? Arch Surg 1989; 124: 805-7. [CrossRef]

14. Nagy KK, Krosner SM, Roberts RR, Joseph KT, Smith RF, Barret J. Determining which patients require evaluation for blunt cardiac injury following blunt chest trauma. World J Surg 2001; 25: 108-11. [CrossRef]

15. Reif J, Justice JL, Olsen WR, Prager RL. Selective monitoring of patients with suspected blunt cardiac injury. Ann Thorac Surg 1990; 50: 530-2. [CrossRef]

16. Mataracı I, Polat A, Çevirme D, Büyükbayrak F, Şaşmazel A, Tuncer $E$, et al. Increasing number of penetrating cardiac trauma in a new center. Ulus Travma Acil Cerrahi Derg 2010; 16: 54-8.

17. Janson JT, Harris DG, Pretorius J, Rossouw GJ. Pericardial rupture and cardiac herniation after blunt chest trauma. Ann Thorac Surg 2003; 75: 581-2. [CrossRef]

18. Bruschi G, Agati S, lorio F, Vitali E. Papillary muscle rupture and pericardial injuries after blnt chest trauma. Eur J Cardiothorac Surg 2001; 20: 200-2. [CrossRef]

19. Amorim MJ, Almeida J, Santos A, Bastos PT. Atrioventricular septal defect following blunt chest trauma. Eur J Cardiothorac Surg 1999; 16: 679-82. [CrossRef]

20. Akay T. Kalp ve damar yaralanmaları. TTD Toraks Cerrahisi Bülteni 2010; 1: 75-86.

21. Guyader AL, Bertin F, Laskar M, Cornu E. Blunt chest trauma: a right pulmonary vein rupture. Eur J Cardiothorac Surg 2001; 20: 1054-6. [CrossRef]

22. Zakynthinos EG, Vassilakopoulos T, Routsi C, Charis MD, Zakynthinos S. Early- and late-onset atrioventricular valve rupture after blunt chest trauma: the usefulness of transesophageal echocardiography. J Trauma. 2002; 52: 990-6. [CrossRef]

23. Sturaitis M, McCallum D, Sutherland G, Cheung H, Driedger AA, Sibbald WJ. Lack of significant long-term sequelae following traumatic myocardial contusion. Arch Intern Med 1986; 146(9):1765 - 9. [CrossRef]

24. Lindstaedt M, Germing A, Lawo T, von Dryander S, Jaeger D, Muhr $G$, et al. Acute and long- term clinical significance of myocardial con- tusion following blunt thoracic trauma: results of a prospective study. J Trauma 2002; 52: 479-85. [CrossRef]

25. Campbell NC, Thomson SR, Muckart DJ, Meumann CM, Van Middelkoop I, Botha JB. Review of 1198 cases of penetrating cardiac trauma. Br J Surg 1997; 84: 1737-40. [CrossRef]

26. Ivatury RR, Nallathambi MN, Rohman M, Stahl WM. Penetrating cardiac trauma. Quantifying the severity of anatomic and physiologic injury. Ann surg 1987; 205: 61-6. [CrossRef]

27. Karrel R, Shaffer MA, Franaszek JB. Emergency diagnosis, resuscitation and treatment of acute penetrating cardiac trauma. Ann Emerg Med 1982; 11: 504-17. [CrossRef]

28. Karasu S, Tokat AO, Uzun HA, Kısacık E, Barlas AM, Baran NT. Penetran kalp yaralanmaları. Ankara Üniversitesi Tıp Fakültesi Mecmuası 2010; 63: 115-8.

29. Kamalı S, Aydın MT, Akan A, Karatepe O, Sarı A, Yüney E. Penetrating cardiac injury: factors affecting outcome. Ulus Travma Acil Cerrahi Derg 2011; 17: 225-30. [CrossRef]

30. Tyburski JG, Astra L, Wilson RF, et al. Factors affecting prognosis with penetrating wounds of the heart. J Trauma 2000;48: 587-91. [CrossRef]

31. Andrade-Alegre R, Mon L. Subxiphoid pericardial window in the diagnosis of penetrating cardiac trauma. Ann Thorac Surg 1994; 58 1139-41. [CrossRef]

32. Degiannis E, Bowley DM, Westaby S. Penetrating cardiac injury. Ann R Coll Surg Engl 2005; 87: 61-3.

33. Macho JR, Markison RE, Schecter WP. Cardiac stapling in the management of penetrating injuries of the heart: rapid control of haemorrhage and decreased risk of personal contamination. J Trauma 1993; 34: 711-5. [CrossRef]

34. Mayrose J, Jehle DV, Moscati R, Lerner E, Brooke BA, Abrams BJ. Comparison of staples versus sutures in the repair of penetrating cardiac wounds. J Trauma 1999; 46; 441-3. [CrossRef]

35. O'Connor J, Ditillo M, Scalea T. Penetrating cardiac injury. J R Army Med Corps 2009; 155: 185-90.

36. Kokotsakis J, Panagiotis H, Antonopoulos N, Skouteli E, Athanasiou T, Lioulias A. Intravenous adenosine for surgical management of penetrating heart wounds. Tex Heart Inst J 2007; 34: 80-1.

37. Knott-Craig CJ, Dalton RP, Rossouw GJ, Barnard PM. Penetrating cardiac trauma: Management strategy based on 129 surgical emergencies over 2 years. Ann Thorac Surg 1992; 53: 1006-9. [CrossRef] 